\title{
Módulos combinables. Estructuras contemporáneas del habitar
}

\section{Combinable modules. Contemporary structures of living}

\author{
Becaria Melina Parpal, Directora Griselda Armelini, Director de Proyecto Alberto Maidana
}

CAID: Arquitectura Sustentable, desarrollo experimental de un módulo habitacional con consumo de energía "0", Programa de Becas de Iniciación a la Investigación Científica, Facultad de Arquitectura, Diseño y Urbanismo, Universidad Nacional del Litoral, Santa Fe, Argentina

meliparpal@gmail.com,gris_uno@msn.com,amaidana@fadu.unl.edu.ar

\section{RESUMEN}

Es evidente que los modos de habitar han ido modificándose a lo largo del tiempo. El objetivo de esta investigación es, a través de la arquitectura, plantear un módulo, o combinación de módulos, que sirvan de base para el sostén de las nuevas estructuras del habitar. Se busca que, a partir del uso de los mismos, se pueda vivir cómodamente y de manera accesible, brindando espacios indeterminados y desjerarquizados para la vida tanto privada como la social que buscan responder a las necesidades a un nivel universal, sin embargo, los mismos permitirían cierta personalización de cada unidad habitacional. Para la construcción de estos módulos de 3,6m $\mathrm{x}$ $3,6 \mathrm{~m}$, -considerando una circunscripción de comodidad mínima de 2,8m de diámetro- se considerarán tecnologías de lo industrializado y prefabricado que posibiliten un desarrollo sostenible social y ambiental para la construcción del módulo propuesto.

\section{ABSTRACT}

It is known that the ways of living in our homes have been changing over time. The aim of this study is to propose a module, or combination of modules, as support of the new structures of living. These modules look for the possibility of living in a comfortable and accessible way by providing indeterminate and hierarchical spaces for both private and social life that seek to respond to needs at a universal level. However, like some kind of stacking game, the modules would allow some customization of each housing unit. For the construction of these $3.6 \mathrm{~m} \times 3.6 \mathrm{~m}$ modules, -considering a minimum comfort circumscription of $2.8 \mathrm{~m}$ in diameter- industrialized and prefabricated technologies will be considered to allow a sustainable social and environmental development of the modules proposed.

PALABRAS CLAVES: vivienda-flexible, estructura-base-modular, adaptabilidad.

KEYWORDS: flexible-housing, modular-base-structure, adaptability.

FECHA DE RECEPCIÓN: 01/9/2021| FECHA DE ACEPTACIÓN: 08/11/2021

DOI: $\underline{\text { http://dx.doi.org/10.30972/arq.0185673 }}$ 


\section{METODOLOGÍA}

La metodología consta de un relevamiento de las necesidades actuales y posibles futuras del hombre, el estudio del comportamiento social y los usos habitacionales. Así como la búsqueda de bibliografía y antecedentes que puedan servir a la formación de una idea teórica y global del trabajo a realizar. Para tal fin se emplearon métodos cualitativos que permitieron elaborar un estado general contextual como soporte teórico de la investigación y métodos cuantitativos relacionados con datos censales de información numérica que respaldan lo teórico cualitativo. Se evalúan tecnologías relacionadas con sistemas de acondicionamiento y generación de energías factibles de ser aplicadas a la investigación al mismo tiempo se seleccionan sistemas constructivos que permitan adaptarse a las condiciones del proyecto. Se aplican métodos cualitativos y cuantitativos de evaluación que permitan determinar propiedades, disponibilidad en el mercado nacional.

Una vez generado este cuerpo de conocimiento se busca comenzar a transportar lo investigado al caso de estudio formulando el dispositivo modular propuesto y algunas combinaciones posibles.

\section{DESARROLLO}

Podemos considerar a los diversos modelos de agrupaciones como unidades de convivencia, (SARQUIS, 2006. Arquitectura y modos de habitar, pp. 25-30),

Tomamos los datos del Censo Nacional 2010 -Tablas 1; 2 y 3- realizado por el INDEC debido a que el correspondiente al año 2020 finalizará a mediados de 2021.

La vida en un hogar ha ido modificándose. Debemos considerar que las personas mayores muchas veces necesitan de asistencia en la misma unidad habitacional o en otras viviendas preparadas para ese fin. También crecen las viviendas donde se convive provisionalmente con otras personas (generalmente entre estudiantes). Otras veces, las personas tienen un hogar principal y viviendas secundarias en otros lugares.

Por otro lado, los hogares unipersonales han aumentado considerablemente, y al mismo tiempo, los hogares extendidos (familiares y parientes) y los hogares compuestos (familiares y no familiares) también aumentan. Los hogares con "jefe mujer" crecen considerablemente. Aumenta la cantidad de DINKYs (Double Income No Kids Yet).

Las tecnologías actuales de comunicación aparecen en la mayoría de los hogares y en aumento como algo que caracteriza los modos de vivir contemporáneos. En cuanto a la vida en casa, y relacionado también con el avance tecnológico, las personas viven mayores cantidades de tiempo en sus casas debido, por ejemplo, al teletrabajo. Sobre la pandemia producida por la dispersión del virus COVID-19. Se evidenciaron los problemas dentro de los hogares en relación a los espacios debido a la cantidad de tiempo que debíamos pasar dentro de un mismo lugar donde realizamos todas las actividades: cocinar, dormir, comer, usar el baño, pero también trabajar, hacer ejercicio, mirar películas, estudiar, realizar videollamadas, practicar piano, hacer música, dibujar, pintar, entre otras cosas que responden a las particularidades y gustos de cada integrante y de cada familia.

Tabla 1: Departamento La Capital, Santa Fe - Tipo de unidad de convivencia.

\begin{tabular}{|l|r|r|r|r|r|r|}
\hline Tipo & Hogar Unipersonal & Hogar Nuclear & Hogar Extendido & Hogar Compuesto & Jefe Varón & \multicolumn{1}{c|}{ Jefe Mujer } \\
\hline Censo 2001 & 140.242 & 562.458 & 153.088 & 9.883 & 639.689 & 232.606 \\
\hline Censo 2010 & 195.314 & 645.845 & 161.461 & 11.387 & 680.746 & 343.162 \\
\hline
\end{tabular}

Fuente: Censo Nacional 2010 - INDEC

Tabla 2: Departamento La Capital, Santa Fe- Tipo de hogar. 
Módulos combinables. Estructuras contemporáneas del habitar

Parpal, Armelini, Maidana

\begin{tabular}{|l|r|r|r|r|r|r|}
\hline Cant. pers. / tipo & \multicolumn{1}{c|}{ Casa } & \multicolumn{1}{c|}{ Rancho } & \multicolumn{1}{c|}{ Casilla } & Departamento & Habitación & lo construido $\mathrm{p} / \mathrm{h}$ Vivienda móvil \\
\hline Censo 2001 & 417.743 & 7.005 & 6.495 & 48.859 & 6665 & 435 \\
\hline Censo 2010 & 455.223 & 5.145 & 3.587 & 54.819 & 827 & 122 \\
\hline
\end{tabular}

Fuente: Censo Nacional 2010 - INDEC

Tabla 3: Departamento La Capital, Santa Fe - Cantidad de usuarios en la misma unidad de convivencia.

\begin{tabular}{|c|c|c|c|c|c|c|c|}
\hline Cant. personas & 1 & 2 & 3 & 4 & 5 & 6 & 7 y más \\
\hline Censo 2001 & 24.953 & 32.058 & 27.368 & 27.649 & 19.531 & 10.749 & 12.547 \\
\hline Censo 2010 & 30.992 & 38.657 & 32.857 & 29.789 & 16.889 & 9.289 & 6.650 \\
\hline
\end{tabular}

Fuente: Censo Nacional 2010 - INDEC.

\section{Breve análisis tipológico.}

En primer lugar notamos las principales ubicaciones de núcleos húmedos tanto centrados en la composición como también desplazados sobre un costado. -Figura 1-
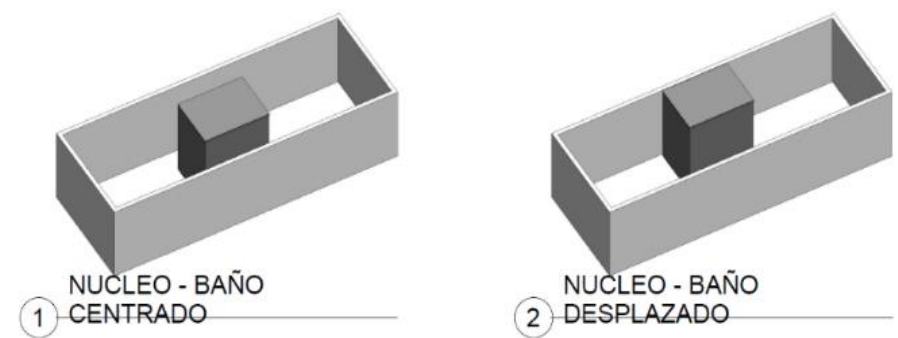

Figura 1: Ubicaciones de núcleos húmedos.

Fuente: Elaboración propia.

A partir del prototipo universal propuesto por la provincia de Santa Fe, podemos observar la ubicación de un módulo habitable con la concentración del núcleo húmedo planteando posibles expansiones hacia los lados (horizontalmente) como en elevación. - Figura 2 -.
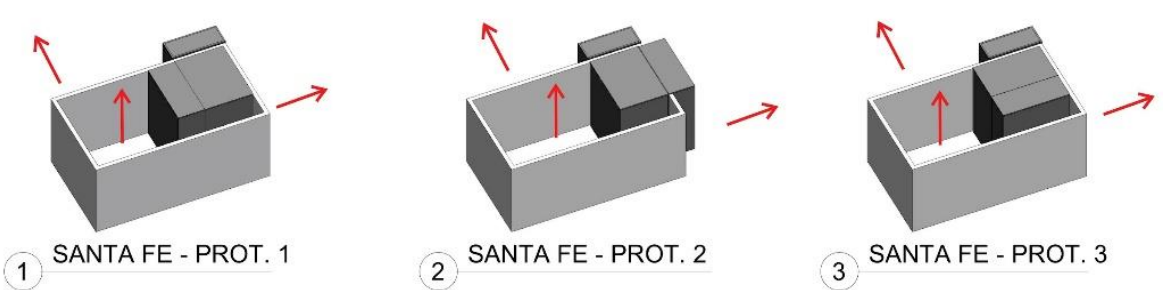

Figura 2: Módulo bases y expansiones tomados a partir del prototipo universal de la provincia de Santa Fe Fuente: Elaboración propia.

Otros proponen un sistema a partir de módulos funcionales. Cada volumen tiene una función distinta y la combinación de los mismos da resultado a la forma final. -Figura 3-.

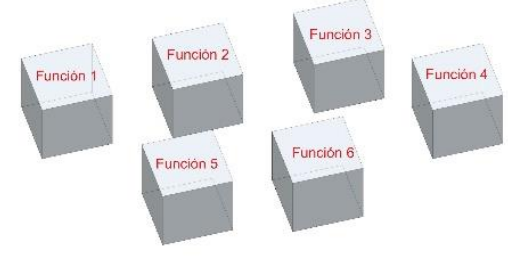

1 MOdULOS FUNCIONALES

Figura 3: Propuestas modulares a partir de la agrupación de funciones. 
A partir de los mismos, algunos proponen la composición a partir de uno de ellos. Los casos que se repiten son a partir de un patio o un vacío central o bien con un baño en el centro. Figura 4.

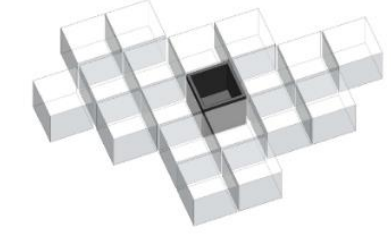

1. LGIOAA COMPOSITVA.
MODULOS FUNCIONALS

Figura 4: Propuesta compositiva de módulos. Fuente: Elaboración propia.

Otras opciones de combinación modular es a partir de proponer una estructura que permita la flexibilidad necesaria para poder elegir las distintas situaciones interiores. -Figura 5-.

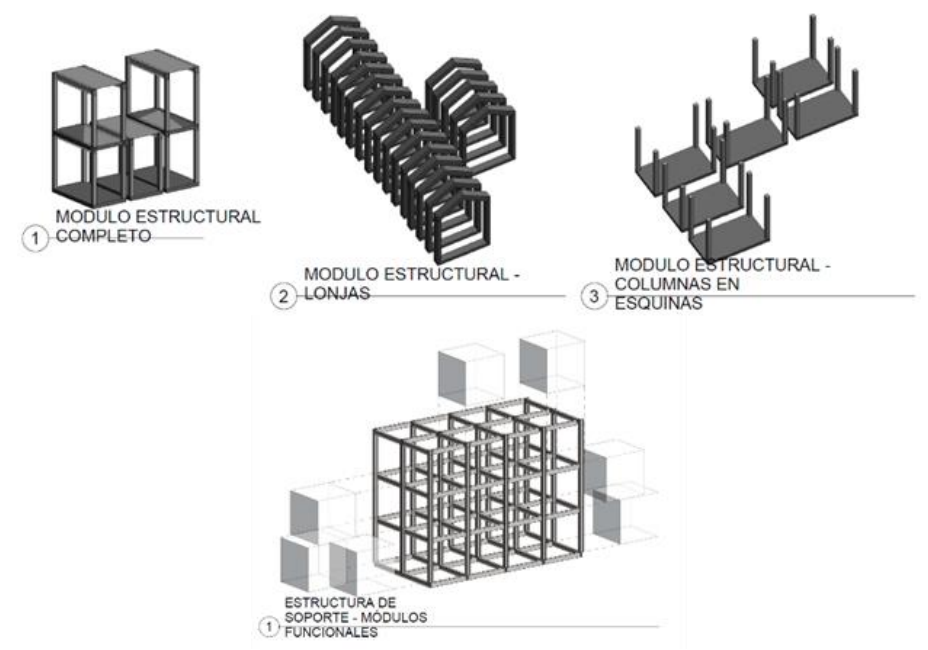

Figura 5: Módulos estructurales. Fuente: Elaboración propia.

En los casos siguientes, se proponen módulos habitables definiendo los espacios interiores a partir de espacios de guardado o núcleos de servicio. -Figura 6-.
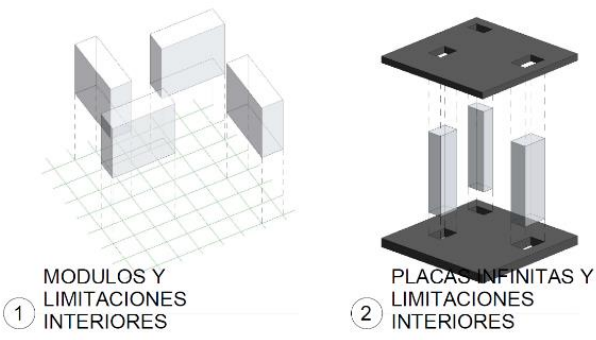

Figura 6: límites interiores por núcleos duros. Fuente: Elaboración propia.

En este caso, -relacionado con las propuestas de la Casa prefabricada simple de Jean Nouvel, 2016, París- se proponen módulos habitables pero las limitaciones con el exterior vienen definidas pudiendo combinar núcleos húmedos como distintos tipos de cerramientos. -Figura 7- 


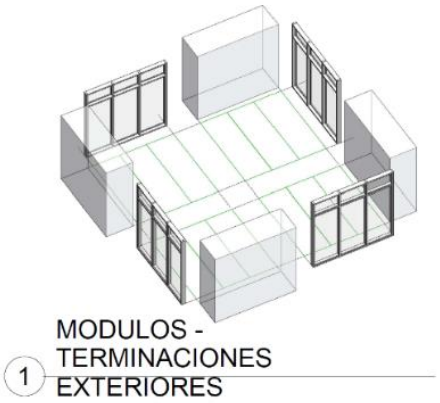

Figura 7: Módulos acabados. Limitaciones exteriores por núcleos duros. Fuente: Elaboración propia.

Para la propuesta del módulo se tiene en cuenta, como sugerencia tecnológica, la Teoría de los Soportes de John Habraken, 1962

Un soporte es la parte de una estructura habitable que viene predeterminada por el diseñador y sobre la cual el residente no tiene control individual.

Esta teoría busca darle mayor lugar a la decisión del espacio habitable al propio residente brindando una cáscara vacía donde la/s persona/s decidan la distribución de su hogar. Entonces, cada unidad de vivienda (bajo la estructura de un soporte), debe permitir un número de diferentes distribuciones. Además, se debe poder cambiar la superficie de la planta, ya sea por adiciones o por cambios de los límites de las unidades dentro del soporte.

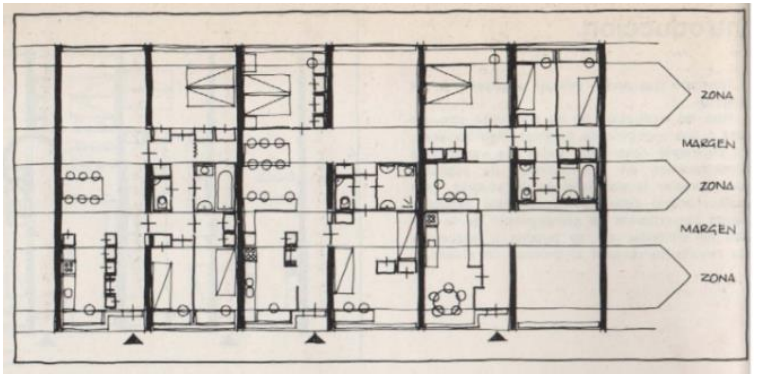

Figura 8: John Habraken, sobre la Teoría de los Soportes, 1962.

Fuente: Recuperado de https://nuevasalternativasparaelhabitatcontemporaneo.files.wordpress.com/2014/03/clase$\underline{\text { teorica-04-habraken.pdf }}$

\section{DISCUSIÓN DE RESULTADOS}

Hacer una arquitectura de presentación, (SARQUIS, 2006. Arquitectura y modos de habitar, pp. 19.), para un usuario incognoscible a priori, debe dar la posibilidad de que cada persona que va a habitarlo pueda desarrollar las actividades y usos que desee. Por ello, planteo el uso de módulos que permitan diversas combinaciones para que el usuario pueda disponerlo según la necesidad, con determinada flexibilidad interior y agrupación de módulos. Además, la tecnología puede variar según el clima y la implantación de manera que en una zona húmeda, por ejemplo, los techos sean inclinados.

Por otro lado, una manera de abaratar costos es empleando estructuras capaces de contener grandes luces y fachadas con repeticiones equidistantes teniendo en cuenta las dimensiones de los productos industriales para la generación de una grilla modular que permita la composición con elementos ya existentes en el mercado local. En este sentido, la adopción de un sistema constructivo en seco como podría ser por ejemplo el Platform Frame, permite un montaje fácil, rápido, económico y con posibilidades de cambios a posteriori.

Las medidas recomendadas para un módulo habitable es de aproximadamente 9m2 o 10m2. 
A modo de verificación de medidas se toman los datos del Código de Edificación CEDOM en Argentina.

comedor / estar / estar - comedor -> lado mínimo 2,8m. | 9m2.

estar comedor - dormitorio ->11m. |15m2. + cocina -> 18m2

dormitorio $->2,5 \mathrm{~m} . \mid 7,5 \mathrm{~m} 2$. (20\% iluminados $+5 \%$ ventilados)

expansión $\rightarrow 1 \mathrm{~m} \mid 1 \mathrm{~m} 2$

cocina $->1,5 \mathrm{~m} \mid 3 \mathrm{~m} 2$. -> circulación -> 0,9 m.

baño $->1,5 \mathrm{~m}$. | 3m2. (ventilados)

toilette $->0,9 \mathrm{~m} . \mid 1,5 \mathrm{~m} 2$. (ventilados)

En conclusión, el lado mayor mínimo requerido es de 2,8m. Sin embargo, en este trabajo, lo retomo como una verificación dimensional ya que se nos recomienda, en el texto de Montaner, Muxí y Falagan, debemos evitar el uso de los mínimos establecidos porque éstos están pensados para actividades individuales mientras que deberíamos favorecer la visibilidad del espacio y el compartir los espacios y el trabajo en la cocina.

Las medidas de construcción en seco en el mercado son de paneles de $1,2 \mathrm{~m}$. $\times 2,4 \mathrm{~m}$. Por este motivo, la grilla modular adoptada es de 1,2m x 1,2m. y el módulo básico de 3,6m. x 3,6m. considerando así un área de 12,96m2. -Figura 9-.

Además, dentro de estas medidas se consideran también los pasos accesibles con un mínimo reglamentario de $1,10 \mathrm{~m}$.
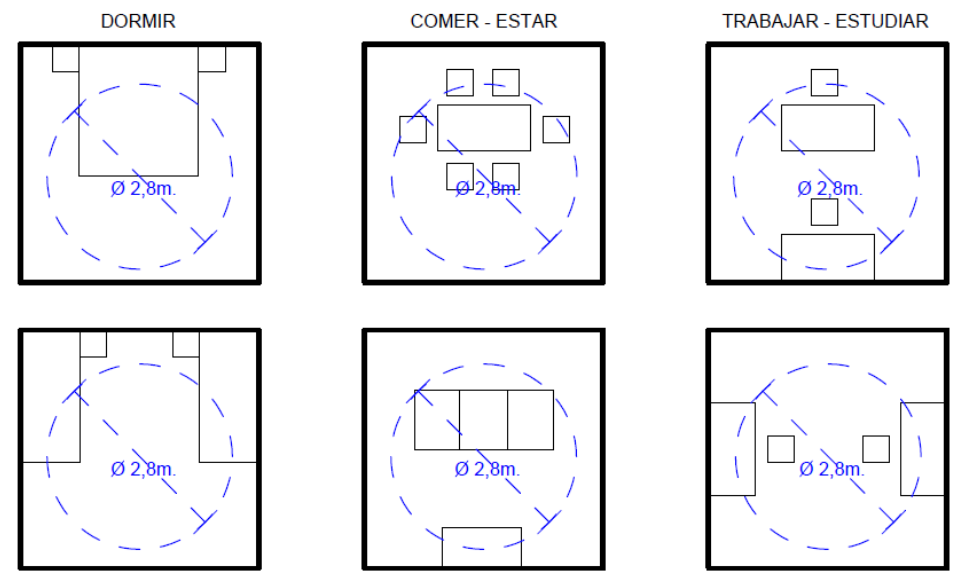

Figura 9: Módulos 3,6m x 3,6m con una circunscripción mínima de comodidad de 2,8m.

Fuente: Gráficos propios concebidos a partir de los ya propuestos por Falagan, D. H, Montaner, J. M, Muxí, Z. en Herramientas para habitar el presente. La vivienda del siglo XXI.

Para realizar distintas combinaciones modulares proponemos historias de vida diversas que darían como resultado posibles soluciones. En los siguientes casos, tenemos en cuenta cuestiones pasivas de regulación energética y tomamos la construcción en entramado de madera como sistema constructivo aplicado al módulo.

Tomamos como referencia dos casos de los siete propuestos:

1. Cecilia tiene 31 años y vive en Santa Fe. Hace poco tiempo empezó a trabajar y su presupuesto no es muy elevado. Hace acrobacia desde su adolescencia pero nunca tuvo espacio en su casa para poder practicarla. Cecilia ama a su perro y le gusta que él también pueda tener su espacio en la casa. Ella está en pareja, sin embargo no vive con ella. No le gusta cocinar y su lugar favorito es el living/comedor. -Figuras $10 ; 11$ y 12 -. 


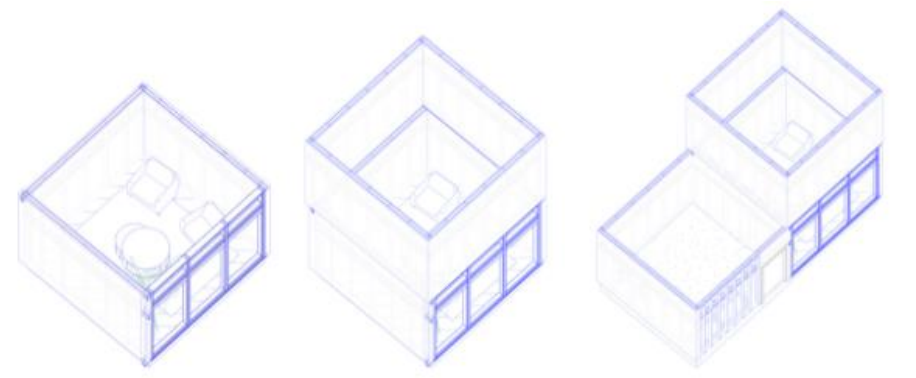

\begin{tabular}{|l|l|l|}
\hline 1. Estar & 2. Estar doble altura & 3. Estar + ingreso/patio \\
\hline
\end{tabular}

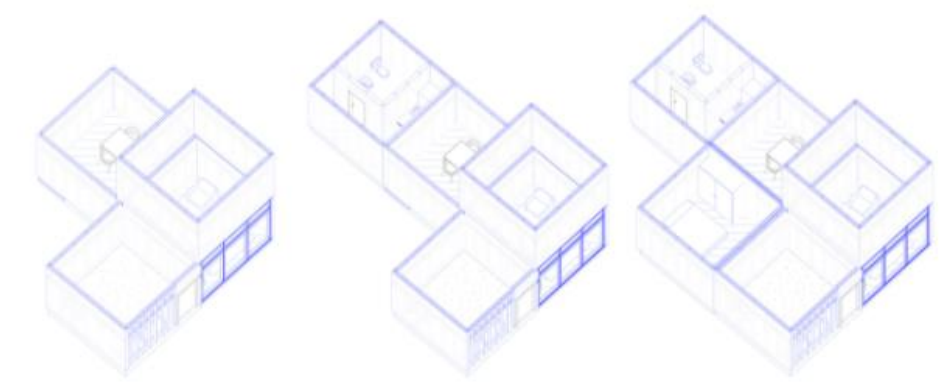

\begin{tabular}{|c|c|c|c|}
\hline $\begin{array}{l}\text { 4. Estar + patio + } \\
\text { comedor }\end{array}$ & & $\begin{array}{l}\text { Estar + patio + } \\
\text { comedor + núcleo } \\
\text { húmedo }\end{array}$ & $\begin{array}{l}\text { 6. Estar + patio + } \\
\text { comedor + núcleo } \\
\text { húmedo + habitación }\end{array}$ \\
\hline
\end{tabular}

Figura 10: Composición modular. Caso 1. Fuente: Elaboración propia.

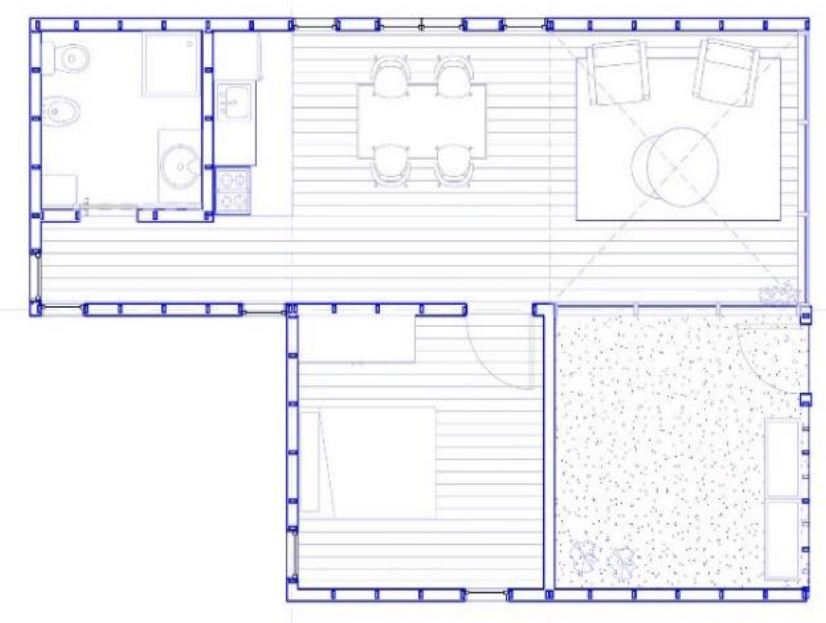

Figura 11: Planta de la composición. Caso 1. Fuente: Elaboración propia. 


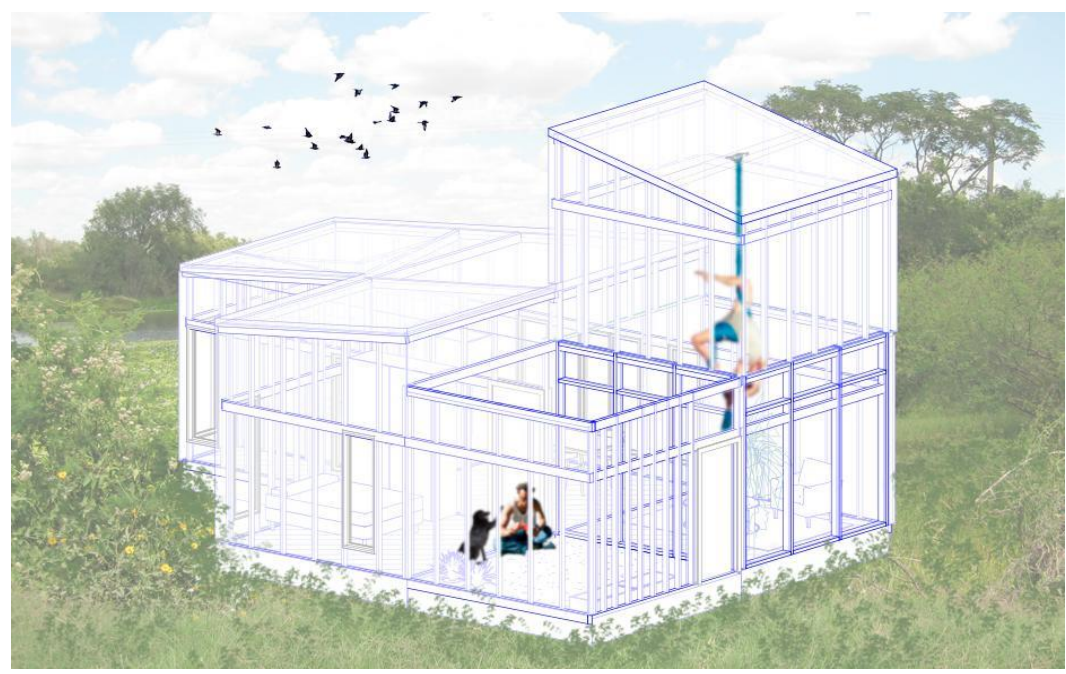

Figura 12: Esquema de la configuración final. Caso 1. Fuente: Elaboración propia

2. Juan tiene 55 años, vive en Mendoza en una casa antigua. A sus 52 años, su madre se fue a vivir con él debido a que ahora estaba sola y su hijo tenía una habitación que le sobraba. Juan es una persona muy trabajadora y se dedica a la herrería. Desde que su madre vive con él, su casa le queda chica para su trabajo. Necesita tener un taller para poder trabajar, un depósito chico y un espacio de atención al público pequeño. -Figuras $13 ; 14$ y 15 .
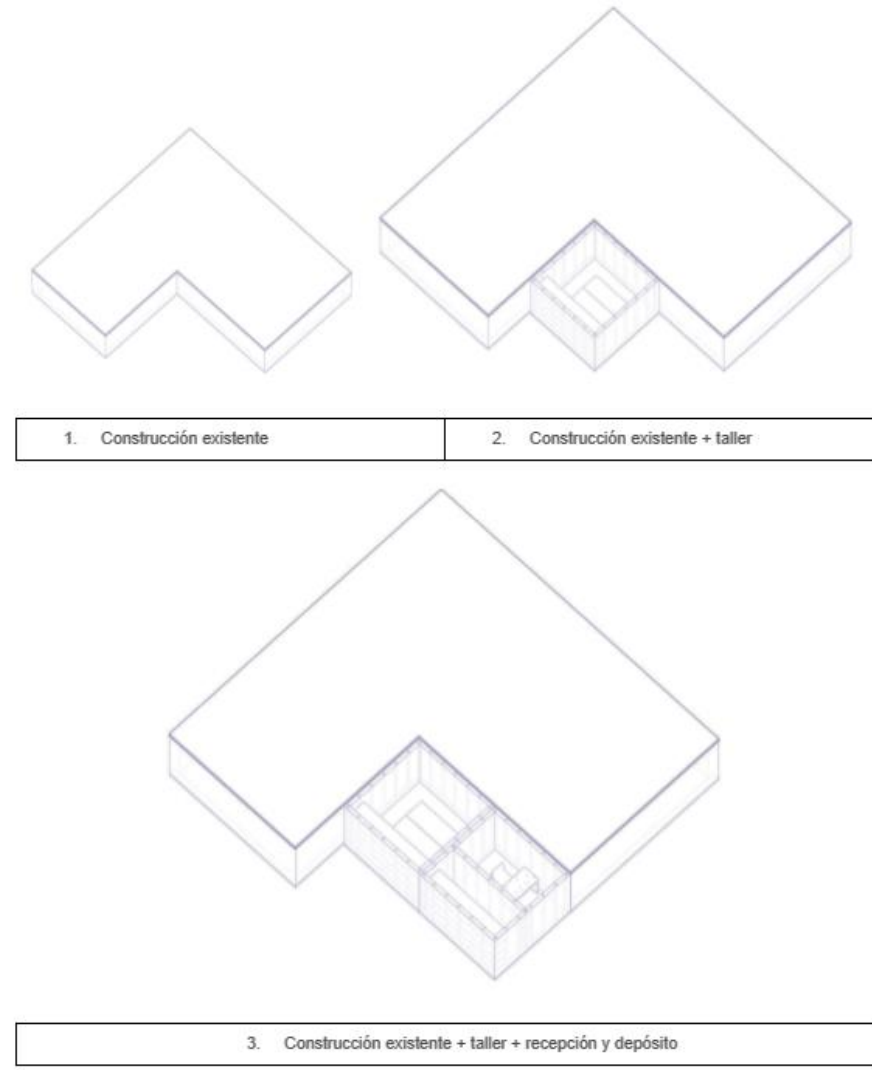

Figura 13: Composición modular. Caso 2 Fuente: Elaboración propia. 


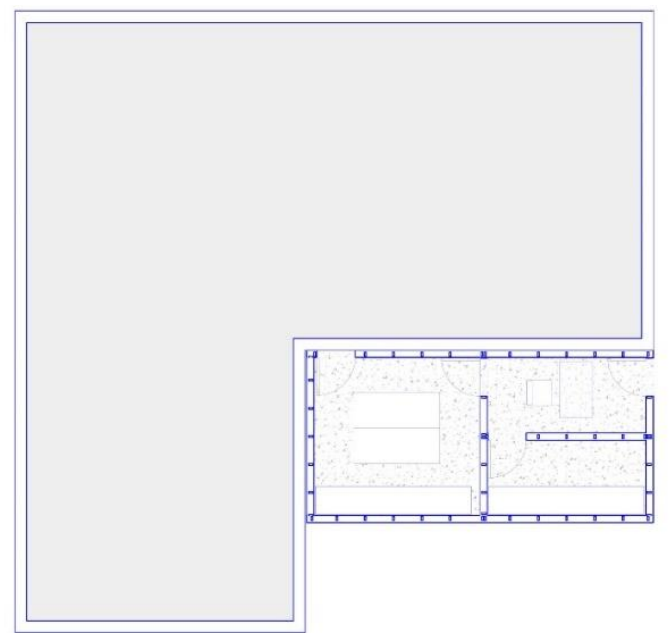

Figura 14: Planta de la composición. Caso 2. Fuente: Elaboración propia.

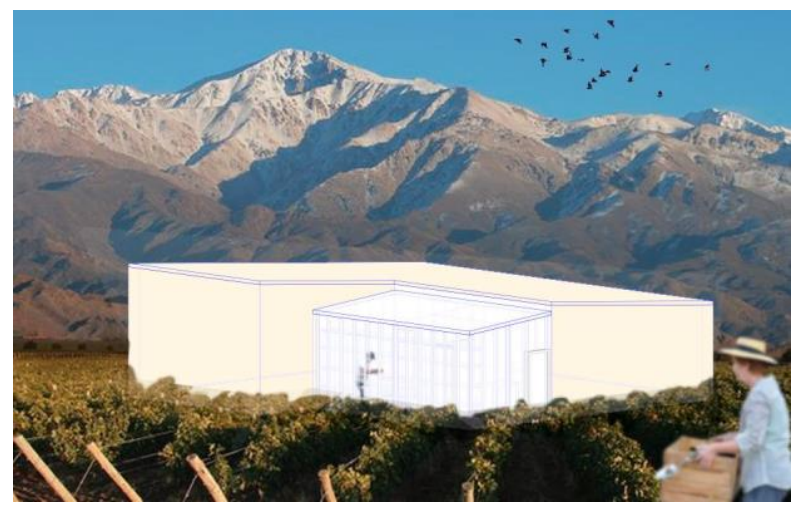

Figura 15: Esquema de la configuración final. Caso 2. Fuente: Elaboración propia

\section{CONCLUSIONES}

Vivimos en un mundo globalizado donde, conforme avanza la sociedad, se conoce, se consume y se modifica constantemente lo cultural (APPADURAI, 2001). Existen afinidades por diversos grupos sociales, diferentes conformaciones de sectores amplios y divergentes, que se entrechocan, se mueven, se modifican, fluyen en el tiempo inmediato o futuro. A medida de que lo cultural va cambiando, varían, de manera constante y, al mismo tiempo, los usos, las necesidades y aspiraciones también lo hacen. De esta manera, se refleja, casi de forma automática, en las maneras de habitar, de usar y crear los espacios.

Quizás, en años anteriores, nadie se hubiese imaginado necesitar o querer tener en su propio hogar un espacio para practicar pole dance o bien, necesitar un espacio para guardar el ahora muy visto en las ciudades y vida diaria: monopatín eléctrico. El hecho de que estas, y otra enorme cantidad de situaciones, gustos, objetos surgen y se renuevan de manera constante, se necesita de un espacio habitable que las contenga y las haga posibles.

Un hogar pensado desde lo flexible, puede convertirse - reconvertirse - y adaptarse a las diferentes necesidades: una casa pequeña se agranda, se modifica por la añadidura 0 eliminación de partes o por cambios en los grupos de convivencia. Quizás un día se necesita que la vivienda sea materializada funcionalmente o constructivamente de una manera que luego puede modificarse, añadiendo tareas, talleres, locales comerciales, salas de trabajo, etc. 
La vivienda se propone entonces como un espacio contenedor que pretende promover el acceso al suelo urbanizado, a la vivienda digna y a la mejora de la calidad de vida a través de criterios de universalidad que busca incorporar e incluir la complejidad de necesidades, capacidades y aspiraciones dentro de la sociedad. De este modo, al considerar lo universal, comprendemos a lo colectivo e incorporamos a todos sin distinciones ni limitaciones conformando un espacio "ideal" donde "lo real", es decir, lo que se va a materializar, va a dar lugar a la identidad de cada usuario debido a que el destinatario, en un principio incognoscible, es incorporado en la conformación del hábitat.

Se busca que el módulo planteado responda a una diversidad tanto formal como de materialización orientada a la captación y aprovechamiento de recursos naturales, económicos y humanos disponibles en el territorio pudiendo alcanzar incluso la autoconstrucción y autogestión ambiental al ser concientizados, educados y/o guiados en el sistema de construcción y en herramientas de acondicionamiento simples. De este modo, se incorporaría aún más al usuario en la sensación de pertenencia hacia su hogar y su lugar en relación con la ciudad y el vecindario.

Es así como los módulos habitables propuestos buscan responder de diferentes maneras las posibles demandas del habitar de un usuario primeramente incognoscible, desjerarquizando los espacios y brindando la posibilidad de que lo universal (el módulo) adquiera identidad y forme parte de la decisión del mismo para su conformación siendo así un lugar (AUGÉ, 1993), para habitar, reconocible por el destinatario como propio y útil para responder a lo que el grupo familiar busca o necesita.

Algunas preguntas para pensar. ¿Pasaste o conoces personas que hayan pasado por modificaciones en su conformación familiar y que esos cambios se traduzcan en espacios funcionales ineficientes? ¿Alguna vez sentiste que tu hogar no respondía a las demandas que tenías? ¿Y hoy? ¿Es tu casa tal cual como la necesitas? ¿Responde a tus aspiraciones?

¿Acaso no vivimos en una sociedad compleja? Pensar desde lo universal y desde las posibilidades, ¿no es esta la manera de ser sostenible social y ambientalmente?

La propuesta pretende tener un carácter evolutivo que atiende a la valorización de la conformación del espacio urbano y del hogar contenedor de las distintas unidades de convivencia. Entonces, las yuxtaposiciones y el dinamismo surgidos en las relaciones sociales en el escenario urbano pueden encontrar su respuesta habitacional en estos módulos habitables combinables.

\section{BIBLIOGRAFÍA}

Appadurai, Arjun. (2001). "La producción de lo local”. En La modernidad desbordada. Trilce/FCE. Pp. 27-62. Buenos Aires, Argentina.

Augé, Marc. (1993). Los no lugares. Espacios del anonimato. Una antropología de la sobremodernidad. Gedisa, Barcelona.

Falagan, David H, Montaner, Josep María, Muxí, Zaida. (2017). "Herramientas para habitar el presente. La vivienda del siglo XXI". Máster Laboratorio de la vivienda del siglo XXI. Universidad Politécnica de Catalunya.

Gausa, Manuel. (2000). Housing + Singular Housing. Actar. Recuperado de: https://es.slideshare.net/santi1594/housingsingular-housing-2

Libro UNACASA. (2015). Competencia UNACASA. Buenos Aires, Argentina. Recuperado de http://unacasa.com.ar/concurso/

Sarquis, Jorge. (2006). Arquitectura y modos de habitar. Nobuko. Buenos Aires, Argentina.

Solá-Morales, Ignasi de, (1995). Cap.: "Arquitectura débil" (pp.61-77) y Cap.: "Lugar: permanencia o producción", (p.p. 101 - 115). en Diferencias. Topografía de la arquitectura contemporánea. GG. Barcelona. 